Article (refereed)

Li, H.; Thompson, I.; Carter, P.; Whiteley, A.; Bailey, M.; Leifert, C.; Killham, K.. 2007 Salivary nitrate - An ecological factor in reducing oral acidity. Oral Microbiology and Immunology, 22 (1). 67-71. doi:10.1111/j.1399-302X.2007.00313.x

Copyright 2007 Blackwell Munksgaard

This version available at http://nora.nerc.ac.uk/2429/

NERC has developed NORA to enable users to access research outputs wholly or partially funded by NERC. Copyright and other rights for material on this site are retained by the authors and/or other rights owners. Users should read the terms and conditions of use of this material at http://nora.nerc.ac.uk/policies.html\#access

This document is the author's final manuscript version of the journal article, incorporating any revisions agreed during the peer review process. Some differences between this and the publisher's version remain. You are advised to consult the publisher's version if you wish to cite from this article.

The definitive version is available at www.blackwell-synergy.com 


\section{Salivary nitrate - An ecological factor in reducing oral acidity}

Hong $\mathrm{Li}^{1 *}$, Ian Thompson ${ }^{1}$, Penny Carter ${ }^{1,2}$, Andrew Whiteley ${ }^{1}$, Mark Bailey ${ }^{1}$, Carlo Leifert ${ }^{3}$ and Ken Killham $^{4}$

${ }^{1}$ Centre for Ecology and Hydrology-Oxford, Natural Environmental Research Council, Mansfield Road, Oxford, OX1 3SR, UK; ${ }^{2}$ Department of Engineering Science, University of Oxford, Oxford, OX1 3PJ, UK; ${ }^{3}$ School of Agriculture, Food \& Rural Development, University of Newcastle, Newcastle upon Tyne, NE1 7RU, UK; ${ }^{4}$ School of Biological Sciences, University of Aberdeen, St Machar Drive, Aberdeen, AB24 3UU, UK.

Background/aims: Human oral cavities represent a novel environment with a constant supply of concentrated nitrate. For humans, over eighty percent of dietary nitrate originates from fruit and vegetables. With a healthy, balanced diet rich in fruit and vegetables, the concentration of nitrate in saliva can reach up to more than three times the European drinking water standard. The physiological function of the active excretion of salivary nitrate is unknown. Furthermore, little is known of the ecological function of oral nitrate and the effect on the oral environment during its subsequent oral microbial conversions. The objectives of the research were to investigate the effect on salivary $\mathrm{pH}$ coupled with oral microbial nitrate and/or nitrite reduction.

Methods: Human saliva samples were incubated anaerobically in the presence of $111.0 \mathrm{mM}$ glucose (2\%), with and without $1.5 \mathrm{mM}$ nitrate/nitrite, and with $\mathrm{pH}$ and nitrate/nitrite consumption measured during the time course of the incubations.

Results: We found that anaerobic incubation of saliva containing a mixture of oral bacteria in the presence of nitrate/nitrite substrates and glucose resulted in a higher $\mathrm{pH}$ than controls in the 
absence of nitrate/nitrite. These results suggest that the presence of these electron acceptors either repressed acid fermentation, or increased alkali production, or consumed acid produced, thus reducing salivary acidity.

Conclusion: This finding identifies salivary nitrate as a possible ecological factor in reducing oral acidity. The possibility that a symbiotic relationship between host nitrate excretion and nitrate reducing microorganism might help protect against tooth decay should be explored further.

Key words: salivary nitrate-oral nitrate reduction-pH-tooth decay

*To whom the correspondence should be addressed. lihong@ceh.ac.uk Accepted by Oral microbiology and immunology (2006) 
Human oral cavities represent a novel environment with a constant supply of concentrated nitrate $(5,19,24)$. Nitrate availability in other natural environments, such as the oceans, on the other hand, is limited by a series of biological processes (12). Human dietary nitrate is absorbed into the bloodstream from the stomach and small intestine, and then concentrated by a factor of 10 to 20 by salivary glands $(2,5,19,24)$. Resultant salivary nitrate concentration ranges between 0.3 to $2.6 \mathrm{mM}$ depending on the diet $(5,19,24)$. Salivary nitrate is dose dependent on dietary nitrate $(5$, $19,24)$ and more than eighty percent of dietary nitrate originates from fruits and vegetables $(32)$. As a result, humans with a healthy, balanced diet rich in fruit and vegetables may have a constant nitrate flow into the oral cavity and its concentration reaches up to more than three times higher than that of the European drinking water standard $(50 \mathrm{mg} / \mathrm{l})(31)$. Most mammals, including humans, also synthesize nitrate $(2,6,7)$. This indigenous nitrate arises from oxidation of nitric oxide (NO), which is a signal molecule and links to numerous biological functions (9). Therefore, even with a nitrate-free diet, there will be significant nitrate concentrations in plasma (2). The physiological function of active salivary nitrate excretion is as yet unknown.

Nitrate is the next most favourable electron acceptor in the environment for micro-organisms conducting energy yielding metabolism when oxygen becomes limited and it is reduced into different nitrogen species in the process $(3,10,30,33)$. This is crucial in the global nitrogen cycle, such as in the removal of nitrate in the marine ecosystem (12). The reduction of nitrate in anaerobic environments is dominated by two dissimilatory processes: respiratory denitrification and dissimilatory nitrate reduction to ammonium (DNRA) $(29,30)$. Salivary nitrate is reduced to 
nitrite and nitrous oxide by oral micro-organisms in humans and animals $(17,19,23,28)$, indicating nitrate respiration is operating in the oral cavity. There have been concerns regarding the harmful effect of salivary nitrite. For example, it has been associated with the formation of nitrosamines, known to be carcinogenic to animals $(18,20,27)$. More recently, increasing evidence suggests that salivary nitrite has beneficial effects to the host, such as anti-microbial activity, which can be enhanced under acidified conditions to prevent stomach and oral infections (19).

When oxygen becomes limited, nitrate respiration takes precedence over the next energyinefficient, fermentation process $(10,33)$. Some bacterial niches in human hosts, such as the interior of dental plaques, are anaerobic $(21,22)$. Nitrate respiration in such niches is energetically less favourable than aerobic respiration, but more favourable than fermentative breakdown of carbohydrates. In fact, most bacteria which carry out DNRA, are also fermentative (29). For oral bacteria with both DNRA and fermentation metabolisms, the supply of nitrate in the oral cavity may activate their nitrate respiration and repress fermentation and, as a result, buffer salivary acidity. Repressing fermentation is not the only effect contributing to a saliva $\mathrm{pH}$ increase due to nitrate respiration. Other mechanisms relating to nitrate reduction, such as hydroxyl ion generation $(8,26)$ and the scavenging of organic acid (3) may further contribute to the reduction of oral acidity. Human saliva contains a high density of micro-organisms detached from oral biofilms $(15,16,21,22)$. When human saliva is incubated with glucose, the $\mathrm{pH}$ has been found to fall due to fermentative metabolism by salivary bacteria $(15,16)$. This has been used as a conventional approach to studying factors affecting oral $\mathrm{pH}$ and tooth decay. 


\section{Materials and methods}

Sampling: A total of 13 volunteers ( 6 males, 7 females) were selected across the age span 20 to 48. Saliva samples were collected by spitting saliva into $20-\mathrm{ml}$ sterile plastic tubes without any stimulation. The total volume for each sample was between 8 to $10 \mathrm{ml}$. For experiments with no pre-incubation, the sample tubes were placed in ice-water during collection. For other experiments, samples were collected at room temperature $\left(20 \pm 3{ }^{\circ} \mathrm{C}\right)$. Samples were stored at $4-8$ ${ }^{\circ} \mathrm{C}$ if not analysed immediately, but were never stored for more than $8 \mathrm{~h}$.

Degassing and pre-incubation: Equal volumes of Milli Q water were added to each saliva sample and mixed thoroughly to reduce viscosity. Aliquots $(2 \mathrm{ml})$ of the diluted saliva samples were then sub-sampled into six 40-ml, sterile, amber vials (triplicate for each treatment) with polypropylene hole caps, and sealed with PTFE/silicone septa (Supelco 27121U). The samples were then degassed with pure nitrogen through a sterile stainless needle (Fisher SZR-370-135X), which was pierced through the septum into the vial, and the tip submerged in the sample. Gas outlet during degassing was carried out via a sterile disposable syringe needle (TERUMO 0411080). To stop contamination during degassing, nitrogen gas was passed through a $0.2 \mu \mathrm{m}$ filter. The degassing procedure was of $10 \mathrm{~min}$ duration, at a rate of approximately $200 \mathrm{ml} \mathrm{min}^{-1}$. After degassing, the samples were incubated at $30^{\circ} \mathrm{C}$ for $12 \mathrm{~h}$ where pre-incubation was applied.

Nitrate reduction assay: Glucose $(\mathrm{BDH})$ and glucose plus nitrate /nitrite (added as potassium nitrate (Sigma) or potassium nitrite (Fisher) respectively) substrate solutions were prepared in the 
sample vials as for the sample preparation from stock solution in Milli Q water. The $\mathrm{pH}$ of the solution was adjusted to 7.0 by addition of $2 \mathrm{M} \mathrm{NaOH}$ and/HCl. The solutions were then degassed as described previously.

Saliva samples and substrate solutions were both placed in a $37^{\circ} \mathrm{C}$ water for 5 min before starting the reaction. The reactions were started by piercing the septa and injecting $3 \mathrm{ml}$ aliquots of substrate solution into saliva sample vials to the final glucose concentration of $111.0 \mathrm{mM}(2 \%)$ and nitrate/nitrite of $1.5 \mathrm{mM}$. Aliquots $(0.8 \mathrm{ml})$ were taken by piercing the septa using a $1 \mathrm{ml}$ sterile, disposable syringe, needle at the time indicated.

Determination of $\mathbf{p H}$ and nitrate/nitrite: Sample $\mathrm{pH}$ was measured in a $1 \mathrm{ml}$ Eppendorf tube, using a micro pH probe (VWR 6621767), attached to a pH meter (JENWAY 3305, UK). Nitrate and nitrite concentrations were determined using an ion chromatography system (Dionex, UK), with conductivity detector and anion exchange column (AS9-HS). The mobile phase was $1.8 \mathrm{mM}$ $\mathrm{NaCO}_{3}$ and $1.7 \mathrm{mM} \mathrm{NaHCO}_{3}$ in water, at a flow rate of $1.5 \mathrm{ml} \mathrm{min}^{-1}$.

Aeration: Where aeration was applied, a similar method was used as for degassing, but air replaced nitrogen during incubation. The air was supplied by an air pump (Whisper 6000, UK) at a rate of approximately $100 \mathrm{ml} \mathrm{min}^{-1}$.

Statistical analysis: All statistical analysis was carried out using MINITAB-14 software. T-tests were carried out using both the $\mathrm{pH}$ value at $3 \mathrm{~h}$ and slopes of $\mathrm{pH}$ change between treatments during incubation. 


\section{Results}

pH fluctuation coupled with nitrate consumption. The $\mathrm{pH}$ fall decreased during incubation with nitrate $(1.5 \mathrm{mM})$ compared with controls (without nitrate) $(\mathrm{P}<0.001$, Paired T-Test, $\mathrm{N}=13)$. A significant relative $\mathrm{pH}$ increase in the nitrate treatment compared to the control during incubation was observed ( $\mathrm{N}=13$, Figure1 (a)). There was a very strong negative correlation between the average nitrate concentration and average relative $\mathrm{pH}$ increase during incubation ( $\mathrm{R}$ $=-0.952, \mathrm{P}=0.012, \mathrm{~N}=13$. Figure 1 (b)). Figure 1 (c) represents an empirical Cumulative Distribution Function plot (CDF). It highlights the $\mathrm{pH}$ differences between the nitrate treatment and control $(\mathrm{N}=13)$ for all saliva samples and at all incubation times, indicating no $\mathrm{pH}$ difference for $\mathrm{pH} 7$ and above for both treatments, but suggesting $\mathrm{pH}$ was generaly lower in control than that in the nitrate treatment during incubation. Approximately 22 percent of data points $(\mathrm{N}=195)$ were less than $\mathrm{pH} 6$ in the control, with only 15 percent of data points $(\mathrm{N}=195)$ less than $\mathrm{pH} 6$ in the nitrate treatment. There were 20 percent of data points less than $\mathrm{pH} 5.8$ in the control, with the same percentage of data less than $\mathrm{pH} 6.3$ in the nitrate treatment.

There were 4 volunteer's samples out of 13 in which $\mathrm{pH}$ fall was not reduced to a significant extent during incubation. Interestingly, nitrate was not consumed in a significant quantity during incubation for these four individuals (data not shown). 
pH fluctuation coupled with nitrite consumption. Nitrous oxide has been detected in human exhaled air (23). In this study, during the reduction of nitrate, the accumulation of nitrite did not account for the loss of nitrate in terms of stoichiometry (data not shown), indicating nitrite is further reduced during microbial nitrate reduction. Indeed, when replacing nitrate with nitrite in a primary experiment using three saliva samples, under the same conditions, the fall in salivary $\mathrm{pH}$ declined significantly in the present of nitrite. Figure 2 shows the relative $\mathrm{pH}$ increase and nitrite concentration at $3 \mathrm{~h}(\mathrm{~N}=3)$. There was no significant $\mathrm{pH}$ difference in one out of 3 samples in the present of nitrite. However, in this experiment, nitrite was not consumed in significant quantities (data not shown). The remaining two samples demonstrated progressive consumption of nitrite, and the relative $\mathrm{pH}$ increase was coupled to nitrite consumption (data not shown).

Factors influencing nitrate consumption and pH fluctuation. When using saliva from one individual, no reduced acidity was observed when nitrate was added and saliva was incubated aerobically, without anaerobic pre-incubation, and there was no consumption of added nitrate. Even nitrate carried over from the original saliva samples, in the control experiment, was not consumed in significant quantities (Figure 3 (a)). The reduced salivary acidity was also observed after addition of nitrate to washed saliva pellets, during anaerobic incubation (Figure 3 (b))

\section{Discussion}

Whole human saliva usually contains $2.6 \mathrm{mM}$ ammonium (11), which is higher than the concentration required to suppress assimilatory nitrate reduction (29). This ensures salivary nitrate is used as an electron acceptor, to support anaerobic nitrate respiration in buffering salivary $\mathrm{pH}$, rather than consumed by assimilatory nitrate reduction by the oral microflora. The 
results suggest that the function of active concentration and excretion of salivary nitrate by humans and animals might have been selected to support anaerobic microbial nitrate respiration that competes for carbon with processes that lead to fermentative acid production; the subsequent nitrate respiration generates hydroxyl ions and scavenges organic acids which have been produced.

Experiments with saliva from one individual also supported the suggestion that the consumption of nitrate is unlikely to have been due to assimilatory nitrate reduction as aeration inhibited nitrate consumption, and assimilatory nitrate reduction is not sensitive to oxygen (29). The washed cell experiment demonstrated that the effect of nitrate on saliva $\mathrm{pH}$ is unlikely to be linked chemically to the supernatant, and is more likely to be associated with the activity of microbial populations in the pellets. In figure 1 (c), differences are mainly apparent below pH 7. The lack of difference above $\mathrm{pH} 7$ between treatments is because data for pHs above 7 mainly reflect the initial incubation conditions (all saliva samples were initially above $\mathrm{pH}$ 7).

The primary experiment showed nitrite also mediated the reduction in acidity during anaerobic incubation, suggesting nitrate was consumed via an anaerobic nitrate respiration pathway. However, the final reduction pathway needs to be further elucidated. Of course one could also expect selective enrichment of denitrifiers (or nitrate-respiring bacteria) when nitrate is available and oxygen is limited (29). Salivary nitrate might have selected an anaerobic, nitrate-respiring microbial community to compete for carbon with obligate, fermentative bacteria. One of the ecological functions of dissimilatory nitrate reduction is to scavenge fermentative products, such as organic acids (3). Salivary nitrate may support the consumption of organic acids, which have 
already been produced in the oral cavity, as electron donors through DNRA and the resultant $\mathrm{pH}$ increase in the oral cavity. The reason for the lack of nitrate reduction in the four out of 13 saliva samples might have been the lower microbial activity in saliva or individual differences in saliva microflora. This is not surprising since samples were collected without control, such as after brushing of teeth, and prior to fluid or food consumption. The same reason might be responsible for one individual result obtained in the experiment with nitrite, which did not indicate either nitrite reduction or acidity reduction. The reason for lack of nitrate/nitrite reduction in these samples should be explored in the future. The lack of acidity and nitrate/nitrite reduction capacities in all these experiments also supports the hypothesis that the slower $\mathrm{pH}$ decrease is linked to microbial metabolism of nitrate or/and nitrite.

It is commonly believed that lactobacilli and streptococci are the main lactic acid producers responsible for tooth decay $(21,22)$. Nitrate may not affect their metabolism as most of them do not reduce nitrate. However, species of Actinomyces are common in human sub-gingival plaque (25), are the main nitrate reducers in the human oral cavity (4) and are carbohydrate fermenting bacteria (14). For these bacteria, suppression of acid production could be theoretically expected when nitrate is available.

In the oral cavity, streptococci ferment carbohydrates to produce lactic acid, which is a principal fermentation substrate used by veillonellae (16). It has been shown that veillonellae from the human oral cavity can reduce nitrate (4). Lactic acid is also produced in the rumen (1). The importance of lactate fermenting bacteria with nitrate reducing capacity in protecting lactate accumulation in rumen (referred to as lactic rumen acidosis) has been postulated. The mechanism 
is based on supplying nitrate to enhance the utilisation of lactate by the nitrate reducing Selenomonas ruminantium (1). In fact, lactate can stimulate nitrate and nitrite reduction to a greater extent than glucose in these bacteria (13). It will be very interesting to investigate the effect of salivary nitrate on the metabolic communication between lactic acid producing communities and lactic acid utilising communities, such as occurs in the rumen. The mechanism of nitrate reduction related oral acid reduction should be further explored.

\section{Acknowledgments}

We are grateful to colleagues for voluntarily providing their saliva samples, to the Centre for Ecology and Hydrology in Oxford for providing the funding and laboratory space, to M. Li for experimental assistance, and to A. Lilly for providing statistical advice.

\section{References}

1.Asanuma, N, Hino, T. Ability to utilize lactate and related enzymes of a ruminal bacterium, Selenomonas ruminantium. Anim. Sci. J. 2005:76:347-352.

2. Benjamin N, McKnight G. Metabolism of nitrate in human-implications for nitrate intake. in: Wilson WS, Ball AS, Hinton RH, ed. Managing risks of nitrates to humans and the environment London. Royal Society of Chemistry, 1999: 281-294.

3. Cole JA. Physiology, biochemistry and genetics of nitrate dissimilation to ammonia. In: Revsbech NP,Sorensen J, ed. Denitrification in soil and sediment. New York: Plenum Press, 1990: 57-76.

4. Doel JJ, Benjamin N, Hector MP, Rogers M, Allaker RP. Evaluation of bacterial nitrate reduction in the human oral cavity. Eur J Oral Sci. 2005:113(1):14-9.

5. Duncan C, Dougall H, Johnston P, Green S, Brogan R, Leifert C, Smith L, Golden M, Benjamin N. Chemical generation of nitric oxide in the mouth from the enterosalivary circulation of dietary nitrate. Nature Med 1995: 1: 546-551. 
6. Green LC, Ruiz de Luzuriaga K, Wagner DA, Rand W, Istfan N, Young VR, Tannenbaum SR. Nitrate biosynthesis in man. Proc Natl Acad Sci USA 1981: 78: 7764-7768.

7. Green LC, Tannenbaum SR, Goldman P. Nitrate synthesis in the germfree and conventional rat. Science 1981: 212: 56-88.

8. Grguric G, Wetmore SS, Fournier RW. Biological denitrification in a closed seawater system. Chemosph 2000: 40: 549-555.

9. Gryglewski RJ, Minus P. ed. Nitric oxide: basic research and clinical application. Amsterdam-Berlin-Oxford-Tokyo-Washington: IOS Press, 2001.

10. Gunsalus RP. Anaerobic Respiration. In: Lederberg J. ed Encyclopedia of microbiology. Vol 2, 2nd edn. San Diego: Acad Press 2000: 180-188.

11. Huizenga JR, Vissink A, Kuipers EJ, Gips CH. Helicobacter pylori and ammonia concentrations of whole, parotid and submandibular/sublingual saliva. Clin Oral Investig 1999: 3: 84-87.

12. Hulth S, Aller RC, Canfield DE, Dalsgaard T, Engström P, Gilbert F, Sundbäck K, Thamdrup B. Nitrogen removal in marine environments: recent findings and future research challenges. Marin Chem 2005: 94: 125-145.

13.Iwamoto M.; Asanuma N.; Hino T. Effects of energy substrates on nitrate reduction and nitrate reductase activity in a ruminal bacterium, Selenomonas ruminantium. Anaerobe, 2001:7: 315-321

14, Kalfas S, Edwardsson S. Effect of culture medium on acid production from sorbitol by oral bacteria. Acta Odontol Scand. 1990: 48(4):217-22.

15. Kleinberg I. A mixed-bacteria ecological approach to understanding the role of the oral bacteria in dental caries causation: an alternative to Streptococcus mutans and the specificplaque hypothesis. Crit Rev Oral Biol Med 2002: 13: 108-125.

16. Kolenbrander PE. Oral microbial communities: biofilms, interactions, and genetic systems. Annul Rev Microiol 2000: 54: 413-437.

17. Li H, Duncan C, Townend J, Killham K, Smith L, Johnston P, Dykhuizen R, Kelly D, Golden M, Benjamin N, Leifert C. Nitrate-reducing bacteria on rat tongues. Appl Environ Microbiol 1997: 63: 203-210.

18. Lijinsky W, Epstein SS. Nitrosamines as environmental carcinogens. Nature 1970: 225: 2123. 
19. Lundberg JO, Weitzberg E, Cole JA, Benjamin N. Nitrate, bacteria and human health. Nat Rev Microbiol 2004: 2: 593-602.

20. Magee PN. Toxicity of Nitrosamines: Their Possible Human Health Hazards. Food and Cosmet Toxicol 1971: 9: 207-218.

21. Marsh P, Marsh PD. Oral ecology and its impact on oral microbial diversity. In: Kuramitsu HK, Ellen RP, ed. Oral bacterial ecology: the molecular basis. Wymondham: Horizon Scientific, 2000: 11-65.

22. Marsh PD. Are dental diseases examples of ecological catastrophes? Microbiol 2003: 149: 279-294.

23. Mitsui T, Kondo T. Effects of mouth cleansing on the levels of exhaled nitrous oxide in young and older adults. Sci Total Environ 1998: 224: 177-180.

24. Pannala AS, Mani AR, Spencer JP, Skinner V, Bruckdorfer KR, Moore KP, Rice-Evans CA. The effect of dietary nitrate on salivary, plasma, and urinary nitrate metabolism in humans. Free Radic Biol Med 2003: 34: 576-884.

25.Paster BJ, Boches SK, Galvin JL, Ericson RE, Lau CN, Levanos VA, Sahasrabudhe A, Dewhirst FE. Bacterial diversity in human subgingival plaque. J. Bacteriol. 2001:183:37703783.

26. Rijn JV, Tal Y, Schreier HJ. Denitrification in recirculating systems: Theory and applications. Agricul Engine (in press, available at wwwelseviercom/locate/aqua-online).

27. Spiegelhalder B, Eisenbrand G, Pressmann R. Influence of dietary nitrate on nitrite content of human saliva: Possible relevance to in vivo formation of $\mathrm{N}$-nitroso- compounds. Fd Cosmet Toxicol 1976: 14: 545-548.

28. Tannenbaum SR, Weisman M, Fett D. The effect of nitrate intake on nitrite formation in human saliva. Fd Cosmet Toxicol 1976: 14: 549-552.

29. Tiedje JM. Ecology of denitrification and dissimilatory nitrate reduction to ammonia. In: Zehnder AJB. ed. Biology of anaerobic microorganisms. New York: Wiley, 1988: 79-244.

30. Unden G, Becker S, Bongaerts J, Schirawski J, Six S. Oxygen regulated gene expression in facultative anaerobic bacteria. Anton van Leeuwenhoek 1994: 66: 3-23.

31. Wold Health Organization (1970) European standards for drinking water (second edition). 
$1970: 33$

32. White JW Jr. Relative Significance of dietary sources of nitrate and nitrite. J Agric Food Chem 1975: 23: 886-891.

33 .Zehnder AJB, Stumm W. Geochemistry and biogeochemistry of anaerobic habitats. In: Zehnder AJB. ed. Biology of anaerobic microorganisms. New York: Wiley, 1988:1-38.

\section{Figure legends}

\section{Figure 1. Fluctuations of salivary $\mathrm{pH}$ and nitrate concentration during anaerobic incubation.}

Figure (a) shows relative $\mathrm{pH}$ increases in nitrate treatment during incubation $(\mathrm{N}=13)$. The values of "relative $\mathrm{pH}$ increase" are calculated from the $\mathrm{pH}$ values in the nitrate treatment deducting the $\mathrm{pH}$ values in control (without nitrate) for all experiments of 13 samples at different times. All samples were pre-incubated and incubated anaerobically during the reaction. (b) Shows the correlation between average nitrate concentration and relative $\mathrm{pH}$ increase $(\mathrm{N}=13)$. (c) Shows the empirical Cumulative Distribution Function (CDF) plots $(\mathrm{N}=13$, each line was plotted from 195 $\mathrm{pH}$ data points). It calculates the proportion of data points less than each $x$ value (pH value), and then plots the proportion (y value) as a function of $x$. The $y$-axis scale represents the percentage of data points less than each $\mathrm{x}(\mathrm{pH})$ value, not a probability scale for a specific distribution. Bars are standard errors of the mean in all figures. 
Figure 2. Effect of nitrite reduction on pH during anaerobic incubation

All conditions are the same as described in Figure 1, except nitrate was replaced by nitrite. Only relative $\mathrm{pH}$ difference and nitrite concentration at $3 \mathrm{~h}$ were plotted $(\mathrm{N}=3)$.

\section{Figure 3. Effects of aeration and saliva supernatant on $\mathrm{pH}$ and nitrate consumption}

The saliva incubation conditions were: (a) no pre-incubation and incubated aerobically; Saliva was washed three times using 1x PBS (phosphate buffered saline), and re-suspended to the original volume. Other procedures were the same as described in methods except without preincubation (b). Each data point represents means from triplicate experiments from a volunteer's saliva sample. 
Figure 1

a

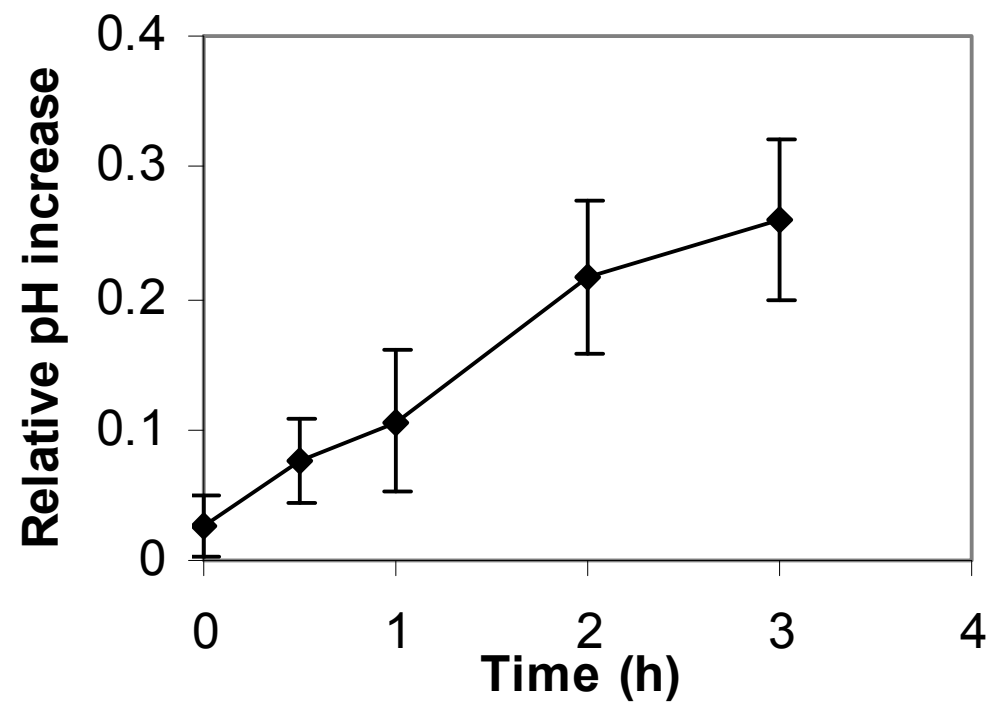

b

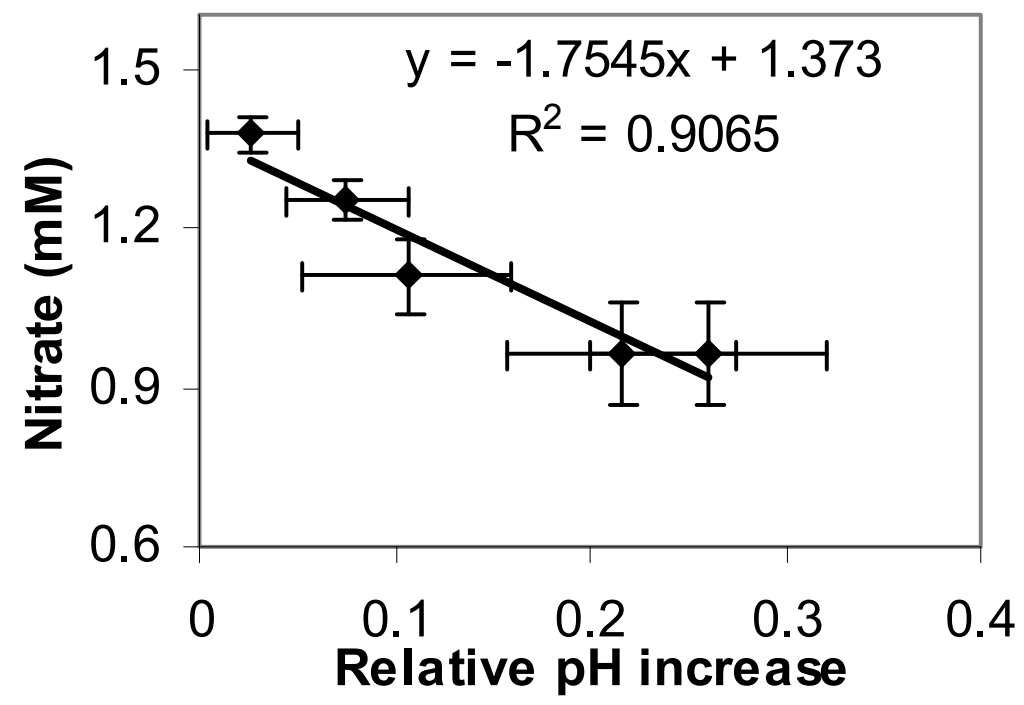


c

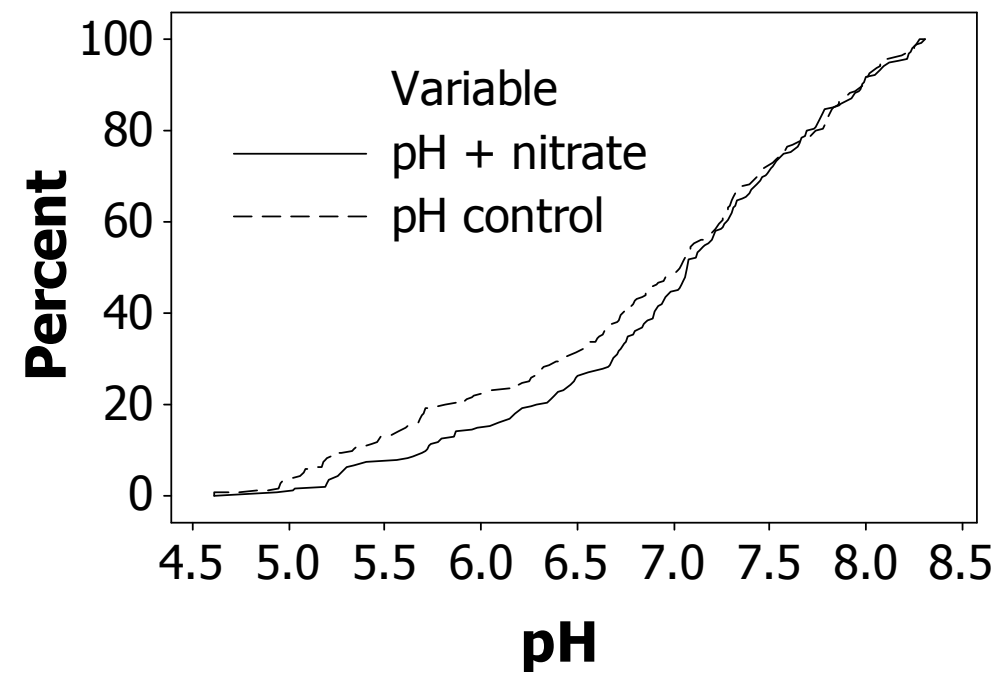


Figure 2






\section{Figure 3}

a.

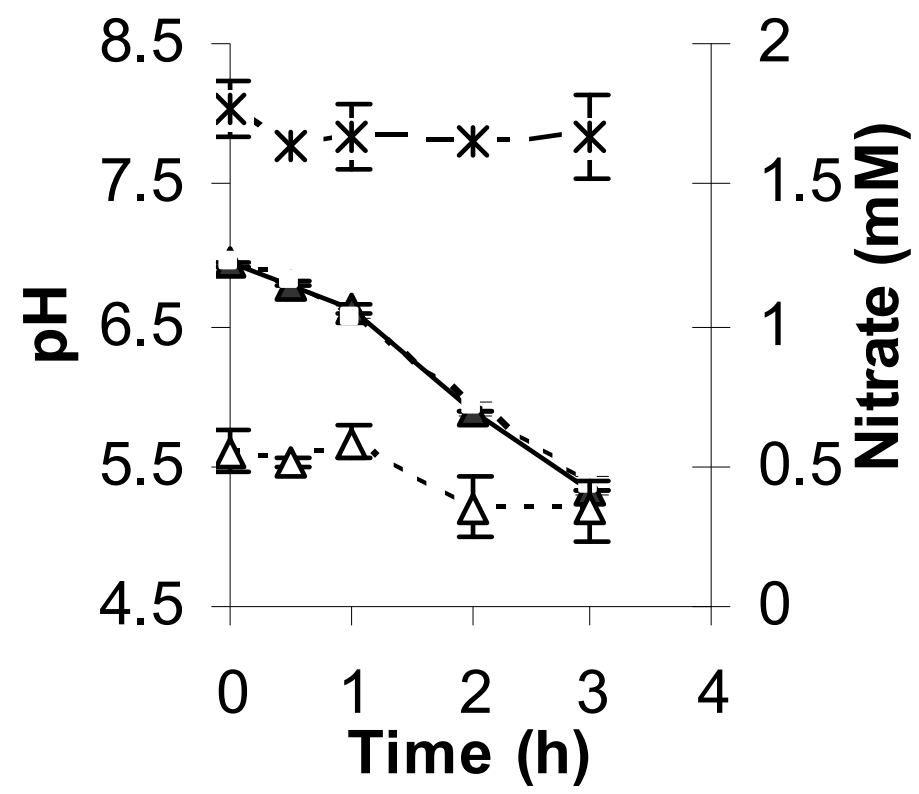

b.

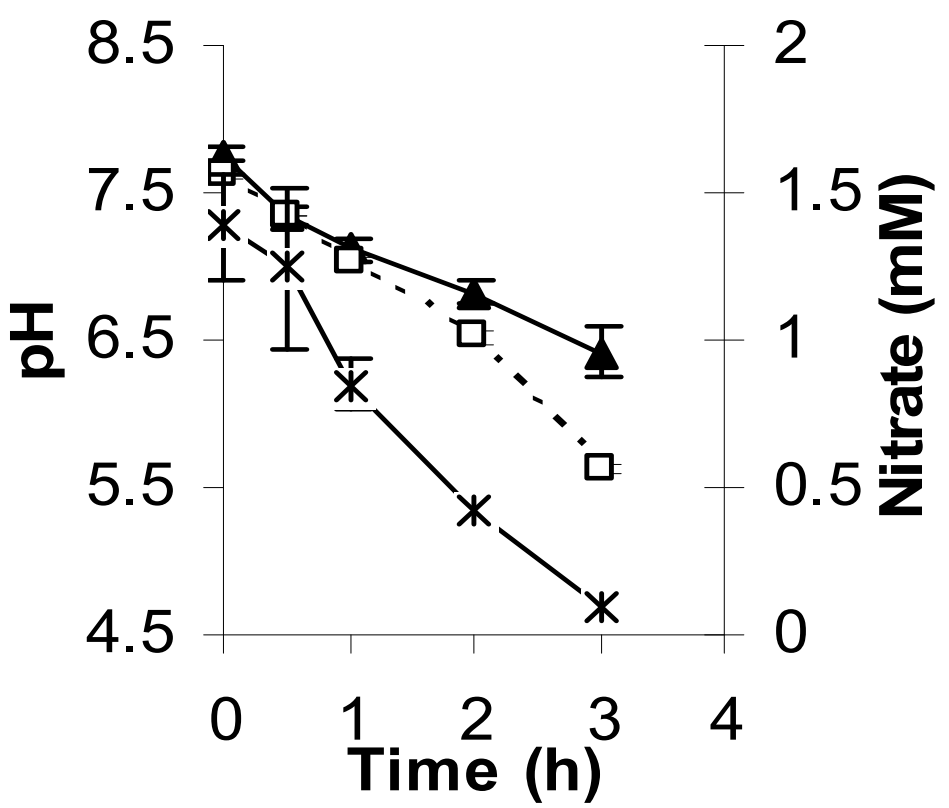


$\longrightarrow \mathrm{pH}+$ nitrate

-. - - - . pH control

$--*--$ nitrate concentration in nitrate treatment

$\Delta$ - nitrate concentration in control 